\title{
Značajne vrste parazita preživača na području Travnika
}

Konjalić, Z.' , Jažić A. ${ }^{2}$, A. Zuko²

Originalni znanstveni rad

\begin{abstract}
SAŽETAK
Na osnovi izvršenih parazitoloških pretraga unutrašnjih organa i poprečno-prugaste muskulature 1.939 preživača (1.006 teladi, 182 junadi, 538 goveda i 213 ovaca) iz individualnog uzgoja, podrijetlom s područja općine Travnik, kod 39,65 \% životinja utvrđeno je prisustvo parazitskih vrsta iz klase Trematoda i larvalnih oblika parazita klase Eucestoda. Utvrđene su četiri vrste parazita, od čega dvije vrste trematoda Fasciola hepatica i Dicrocoelium dendriticum i dvije vrste larvalnih oblika eucestoda, Echinococcus polymorphus (vrste Echinococcus granulosus) $i$ Cysticercus bovis (vrste Taenia saginata). Najveći ukupni postotak infestacije pretraženih preživača od 29,55\% opažen je za ciste Echinococcus polymorphus s najčešćim nalazom u jetri i plućima, a sporadično su nađeni na srcu, slezeni i bubregu. Dvostruko manji nalaz utvrđen je za Dicrocoelium dendriticum, 15,57 \%, zatim Fasciola hepatica 8,45\%, a najmanji je utvrđen za bobice Cysticercus bovis, samo 0,41 \%.

Ključne riječi: paraziti, preživači, trematode, cestode
\end{abstract}

\section{UVOD}

Parazitarne bolesti široko su rasprostranjene uzrokujući oboljenja svih vrsta domaćih i divljih životinja i na taj način nanose velike ekonomske štete stočarstvu. Manifestiraju se manje ili više jasno izraženim simptomima i posljedicama za domaćina. Mortalitet uzrokovan djelovanjem parazita veoma je rijedak, ali su zato indirektne štete izazvane patogenim djelovanjem parazita ili njihovih razvojnih oblika daleko više izražene. Najveći broj parazitarnih bolesti ima kroničan tijek i uglavnom se ne manifestira kliničkim simptomima te zbog toga ne privlače pažnju farmera i ne liječe se.

Također, oboljele životinje predstavljaju izvor zaraze za druge vrste životinja kao i za kontaminaciju prostora i pašnih površina. Na osnovi navedenog, jasan je interes znanosti i struke u rješavanju zdravstvenih problema i ekonomskih šteta koje stočarstvu nanose paraziti i njihovi razvojni oblici. Stoga bez poznavanja epizo- otiološke situacije parazita na određenom području i proračuna ekonomskih šteta kao dodatnog pokazatelja prisustva parazitoza, nije moguće planiranje mjera za suzbijanje i preveniranje značajnih parazitoza, odnosno stvaranja uvjeta za razvoj suvremenog stočarstva.

S obzirom na to da je područje Travnika i plato planine Vlašić tradicionalno stočarski kraj, kao i činjenica da je to područje s najvećim brojem grla po jedinici prostora u Bosni i Hercegovini, željeli smo utvrditi koje su to najznačajnije vrste trematoda i cestoda u preživača s tog područja.

\section{MATERIJAL I METODE RADA}

$U$ razdoblju od 2004. do 2005. godine obavljene su parazitološke pretrage unutrašnjih organa i poprečnoprugaste muskulature 1.939 preživača različitih vrsta i dobnih kategorija, od čega 1.006 teladi, 182 junadi, 538 goveda i 213 ovaca. Sve pretražene životinje potjecale

\footnotetext{
1 Mr.sc. Zijad Konjalić

2 dr. sc. Adnan Jažić, redoviti profesor; dr. sc. Almedina Zuko, redoviti profesor, Katedra za paraziotologiju i invazione bolesti, Veterinarski fakultet Univerziteta u Sarajevu, Zmaja od Bosne 90, Sarajevo, Bosna i Hercegovina
} 
su iz individualnog uzgoja, a podrijetlo životinja bilo je isključivo s područja općine Travnik.

Životinje su pretraživane na prisustvo parazitskih vrsta iz klase Trematoda i larvalnih oblika parazita klase Eucestoda. Pregled se zasnivao na pregledu trupova i organa grudne i trbušne šupljine nakon klaoničke obrade životinja. Prilikom pregleda korištene su metode adspekcije, palpacije i zarezivanje mesa i organa.

Također, obrađeni su podaci po godišnjim dobima, radi utvrđivanja sezonske dinamike parazita. Uzorkovanje navedenih parazita bilo je tijekom cijele godine kod goveda, a u ovaca u proljeće i jesen.

Na osnovi stručne literature (Čanković i Jažić, 1988.; Hendrix, 1998.; Kassai, 1999.; Kaufmann, 1996.; Soulsby, 1986.; Šibalić i Cvetković, 1987.) izvršena je determinacija pojedinih vrsta parazita i njihovih larvalnih oblika, kao i načini parazitoloških pretraga.

\section{REZULTATI I DISKUSIJA}

Parazitološkim pretragama unutrašnjih organa i skeletne muskulature 1.939 preživača iz individualnog uzgoja s područja općine Travnik, kod 39,65 \% životinja utvrđeno je prisustvo parazitskih vrsta iz klase Trematoda i larvalnih oblika parazita klase Eucestoda (Tablica 1.).

Najveći postotak infestacije parazitima registriran je za ovce, svih 213 pretraženih životinja bilo je pozitivno, zatim goveda starosti više od dvije godine $83,27 \%$, junadi $44,50 \%$, a najniža je infestiranost bila za telad $-2,68 \%$.

Tablica 1. Ukupan broj pregledanih, pozitivnih i postotak infestiranih preživača

Table 1. Total number of examined, positive and infected ruminants

\begin{tabular}{|l|c|c|c|}
\hline $\begin{array}{l}\text { Vrsta i kategorija preživača } \\
\text { Species and age categories of ruminants }\end{array}$ & $\begin{array}{c}\text { Pregledano } \\
\text { Examined }\end{array}$ & $\begin{array}{c}\text { Pozitivno } \\
\text { Positive }\end{array}$ & $\%$ \\
\hline Goveda / Cattle & 538 & 448 & 83,27 \\
\hline Junad / Beef cattle & 182 & 81 & 44,5 \\
\hline Telad / Calves & 1006 & 27 & 2,68 \\
\hline Ovce / Sheep & 213 & 213 & 100 \\
\hline UKUPNO / Total & 1939 & 769 & 39,65 \\
\hline
\end{tabular}

Utvrđene su četiri vrste parazita, od čega dvije vrste trematoda Fasciola hepatica i Dicrocoelium dendriticum i dvije vrste larvalnih oblika eucestoda, Echinococcus polymorphus (vrste Echinococcus granulosus) i Cysticercus bovis (vrste Taenia saginata), kao najčešći uzročnici parazitskih bolesti preživača što potvrđuju rezultati istraživanja velikog broja autora iz zemalja u okruženju i šire (Brglez i Kopitar, 1983.; lliev, 1985.; Lepojev i sur., 1985.; Pauković i sur. 1988.; Popović i sur. 1988.; Repač, 1985.; Toriano i sur. 1994.). Obje vrste trematoda utvrđene su kod svih ispitivanih vrsta preživača, dok ciste $\mathrm{E}$. polymorphus nisu registrirane samo kod teladi.

Najveći ukupni postotak infestacije pretraženih preživača od 29,55 \% registriran je za ciste $E$. polymorphus s najčešćim nalazom u jetri i plućima, a sporadično su nađeni na srcu, slezeni i bubregu (grafikon 1.). Dvostruko manji nalaz utvrđen je za $D$. dendriticum $(15,57 \%)$, F. hepatica $(8,45 \%)$, a najmanji je utvrđen za bobice $C$. bovis, samo $0,41 \%$.

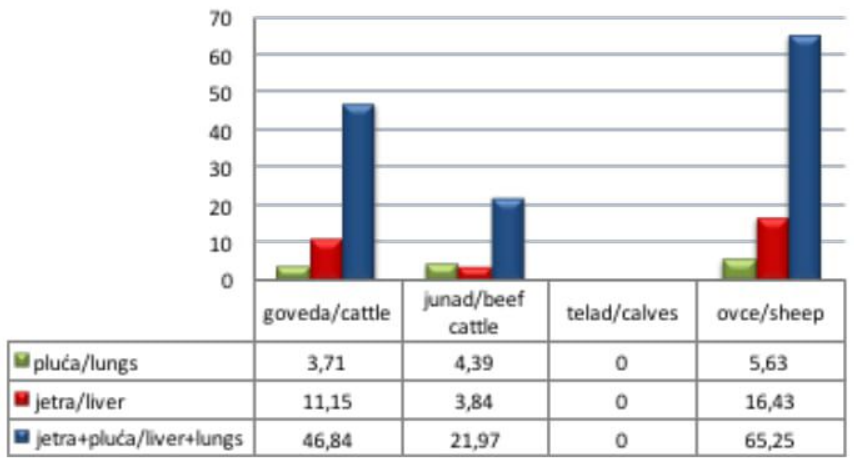

Grafikon 1. Prevalencija infestacije istraživanih preživača s Echinococcus polymorphus po lokalizaciji nalaza cisti

Chart 1. The extensity of infestation investigated ruminants with Echinococcus polymorphus by finding sity of cists

Uspoređujući rezultate naših istraživanja za ciste E. polymorphus kod preživača $s$ rezultatima istraživača $s$ područja BiH i susjednih zemalja (Repač, 1985.; Lepojev i sur., 1985.; Zuko i sur., 1992./95. b; Ferizbegović i sur., 1996.; Zuko i sur., 2000.) uočljivo je da je postotak infestacije veći.

Tablica 2. Prevalencija infestacije ispitivanih preživača vrstama trematoda prema mjestu parazitiranja

Table 2. The prevalence of investigated ruminants with determined of trematoda species according to the place of parasites

\begin{tabular}{|c|c|c|c|c|}
\hline \multirow{3}{*}{$\begin{array}{l}\text { Vrsta i kategorija } \\
\text { preživača } \\
\text { Species and age categori- } \\
\text { es of ruminants }\end{array}$} & \multicolumn{4}{|c|}{ Jetra / Liver } \\
\hline & \multicolumn{2}{|c|}{ Fasciola hepatica } & \multicolumn{2}{|c|}{ Dicrocoelium dendriticum } \\
\hline & $\begin{array}{l}\text { Pozitivno / } \\
\text { Positive }\end{array}$ & $\%$ & $\begin{array}{l}\text { Pozitivno / } \\
\text { Positive }\end{array}$ & $\%$ \\
\hline Goveda / Cattle & 86 & 15,98 & 166 & 30,85 \\
\hline Junad/Beef cattle 182 & 24 & 13,18 & 23 & 12,63 \\
\hline Telad / Calves & 19 & 1,88 & 8 & 0,79 \\
\hline Ovce / Sheep & 35 & 16,43 & 105 & 49,29 \\
\hline UKUPNO /Total & 164 & 8,45 & 302 & 15,57 \\
\hline
\end{tabular}

Prevalencija invadiranosti vrstom $D$. dendriticum iznosila je kod ovaca $49,29 \%$, goveda $30,85 \%$, junadi $12,63 \%$, a najmanja je bila kod teladi, 0,79\% (Tablica 2.). Visoke postotke infestacije malim metiljem u ovaca i goveda zabilježili su i drugi istraživači s područja $\mathrm{BiH}$ (Bjelica, 1964.; Čanković i Rozman, 1979.; Zuko i sur., 2005.), ali i susjednih zemalja (Brglez i Kopitar, 1983.; Pauković i sur. 1988.; Popović i sur. 1988.; Toriano i sur. 1994.), što je u skladu s rezultatima naših istraživanja. Sličnu prevalenciju infestacije kod ispitivanih preživača 
imala je $F$. hepatica (ovce $16,43 \%$ i goveda $15,98 \%$ ). Kod teladi $F$. hepatica je registrirana u samo $1,88 \%$ slučajeva. S obzirom na brdsko-planinsko područje Travničke regije, mogla se očekivati niža infestiranost velikim metiljem, posebno kod ovaca i goveda, te u odnosu na nalaze drugih autora kod kojih je nalaz F. hepatica bio veći (Bjelica, 1964.; Čanković i Rozman, 1979.; Pauković i sur., 1988.; Popović i
Adžić, 1988. Zuko i sur., 1992./95.a; Zuko i sur., 2005.).

Najveći ukupni postotak infestacije s C. bovis (Tablica 3.), utvrđen je kod junadi $2,19 \%$, a za ostale dobne kategorije kretao se od 0,18-0,29\%, što odgovara nalazima Zuko i sur. (2005.), dok su veće vrijednosti registrirali autori u svojim istraživanjima iz 60-ih godina prošlog stoljeća (Alagić i sur. 1964.; Mijatović, 1964.; Rukavina, 1962.).

Tablica 3. Prevalencija infestacije ispitivanih preživača utvrđenim vrstama eucestoda prema mjestu parazitiranja

Table 3. The prevalence of investigated ruminants with determined of cestoda species according to the place of parasites

\begin{tabular}{|c|c|c|c|c|c|c|c|c|}
\hline \multirow{3}{*}{$\begin{array}{l}\text { Vrsta i kategorija preživača } \\
\text { Species and age categories of } \\
\text { ruminants }\end{array}$} & \multirow{2}{*}{\multicolumn{2}{|c|}{$\begin{array}{c}\text { Cysticercus bovis } \\
\text { Muskulatura / Musculature }\end{array}$}} & \multicolumn{6}{|c|}{ Echinococcus polymorphus } \\
\hline & & & \multicolumn{2}{|c|}{ Jetra + pluća / Lungs + liver } & \multicolumn{2}{|c|}{ Pluća / Lungs } & \multicolumn{2}{|c|}{ Jetra / Liver } \\
\hline & $\begin{array}{l}\text { Pozitivno / } \\
\text { Positive }\end{array}$ & $\%$ & $\begin{array}{l}\text { Pozitivno / } \\
\text { Positive }\end{array}$ & $\%$ & $\begin{array}{l}\text { Pozitivno / } \\
\text { Positive }\end{array}$ & $\%$ & $\begin{array}{c}\text { Pozitivno / } \\
\text { Positive }\end{array}$ & $\%$ \\
\hline Goveda / Cattle & 1 & 0,18 & 252 & 46,84 & 20 & 3,71 & 60 & 11,15 \\
\hline Junad / Beef cattle 182 & 4 & 2,19 & 40 & 21,97 & 8 & 4,39 & 7 & 3,84 \\
\hline Telad / Calves & 3 & 0,29 & - & - & - & - & - & - \\
\hline Ovce / Sheep & - & - & 139 & 65,25 & 12 & 5,63 & 35 & 16,43 \\
\hline UKUPNO 1939 & 8 & 0,41 & 431 & 22,22 & 40 & 2,06 & 102 & 5,26 \\
\hline
\end{tabular}

Prateći sezonsku dinamiku ukupnog broja pregledanih $\mathrm{i}$ infestiranih preživača po godišnjim dobima, stopostotna infestiranost registrirana je za ovce, dok se za goveda kretala od 75,58 \% u proljeće do $95,74 \%$ u zimskom razdoblju. Za junad najniža infestiranost bila je u proljeće $-42,85 \%$, a najveća u ljetnom razdoblju - 46,87 \%. Najniža je infestiranost utvrđena kod teladi i kretala se od 1,58 \% zimi do $3,57 \%$ u ljetnom razdoblju (Tablica 4.).

Tablica 4. Ukupan broj pregledanih, pozitivnih i postotak infestiranih preživača po godišnjim dobima

Table 4. Total number of examined, positive and infected ruminants according to the seasonst

\begin{tabular}{|c|c|c|c|c|c|c|c|c|c|c|c|c|}
\hline \multirow{2}{*}{$\begin{array}{l}\text { Vrsta } \\
\text { Species }\end{array}$} & \multicolumn{3}{|c|}{ Proljeće / Spring } & \multicolumn{3}{|c|}{ Ljeto / Summer } & \multicolumn{3}{|c|}{ Jesen / Autumn } & \multicolumn{3}{|c|}{ Zima/Winter } \\
\hline & $\begin{array}{l}\text { Preg. } \\
\text { Exam. }\end{array}$ & $\begin{array}{l}\text { Poz. } \\
\text { Pos. }\end{array}$ & $\%$ & $\begin{array}{l}\text { Preg. } \\
\text { Exam. }\end{array}$ & $\begin{array}{l}\text { Poz. } \\
\text { Pos. }\end{array}$ & $\%$ & $\begin{array}{l}\text { Preg. } \\
\text { Exam. }\end{array}$ & $\begin{array}{l}\text { Poz. } \\
\text { Pos. }\end{array}$ & $\%$ & $\begin{array}{l}\text { Preg. } \\
\text { Exam. }\end{array}$ & $\begin{array}{l}\text { Poz. } \\
\text { Pos. }\end{array}$ & $\%$ \\
\hline Goveda / Cattle & 172 & 130 & 75,58 & 174 & 150 & 86,2 & 98 & 78 & 79,59 & 94 & 90 & 95,74 \\
\hline Junad / Beef cattle & 56 & 24 & 42,85 & 32 & 15 & 46,87 & 51 & 22 & 43,13 & 43 & 20 & 46,51 \\
\hline Telad / Calves & 296 & 7 & 2,36 & 308 & 11 & 3,57 & 213 & 6 & 2,81 & 189 & 3 & 1,58 \\
\hline Ovce / Sheep & 76 & 76 & 100 & - & - & - & 137 & 137 & 100 & - & - & - \\
\hline
\end{tabular}

Paraziti i razvojni oblici parazita utvrđeni su najčešće u miješanim infestacijama kod svih dobnih kategorija ispitivanih životinja, izuzev kod teladi.

Kod goveda, bez obzira o kojoj se dobnoj kategoriji radilo, E. polymorphus je bio najčešće zastupljen. Spomenute ciste utvrđene su u čistoj ili u miješanoj infestaciji s ostalim dvjema vrstama utvrđenih trematoda.

Kod ovaca je također zastupljenost $E$. polymorphus bila dominantna u čistoj invaziji ili u miješanoj, najčešće s D. dendriticum (Tablica 5.).

Kod goveda je sezonska dinamika čiste infestacije $s$ E. polymorphus iznosila od $24,41 \%$ u proljeće do 53,19 $\%$ u zimskom razdoblju. U miješanoj je invaziji najčešći bio nalaz vrsta $E$. polymorphus $+D$. dendriticum koji se kretao od $8,51 \%$ zimi do $26,43 \%$ ljeti. Ostale vrste parazita u miješanoj invaziji nađene su u malom postotku. $Z a$ vrstu $D$. dendriticum najveća prevalencija zabilježena je u jesenjem razdoblju i iznosila $20,40 \%$, a najniža od $2,12 \%$ u zimskom. Prevalencija F. hepatica kretala se od $5,74 \%$ ljeti do $17,02 \%$ zimi. Našim rezultatima istraživanja odgovaraju rezultati Zuko i sur. (1992./95.a) koji su pokazali najveću zastupljenost $D$. dendriticum u svibnju i kolovozu (61,5\%), a najmanju u siječnju $(9,0 \%)$, dok je $F$. hepatica najčešće utvrđena u listopadu $(83,3 \%)$, a najmanja prevalencija zabilježena u veljači bila je16,6 $\%$. Prema istim autorima, za ciste E. polymorphus najmanja prevalencija invadiranosti bila je u rujnu (15,3\%), a najveća u ožujku $(64,2 \%)$.

Kao i kod goveda, ciste E. polymorphus u jetri junadi u najvećem su postotku utvrđene u zimskom razdoblju $(20,93 \%)$, a najniži postotak od $7,14 \%$. zabilježen je u proljeće. U miješanoj infestaciji E. polymorphus je u puno manjem postotku utvrđen $\mathrm{s} D$. dendriticum i $F$. hepatica. Pojedinačni nalaz $D$. dendriticum kretao se od 3,12 \% ljeti 


\section{Znanstveno stručni dio}

Tablica 5. Utvrđene vrste parazita jetre i pluća kod ispitivanih preživača u čistoj i miješanoj infestaciji

Table 5. The established parasites of liver and lungs in the examined ruminants in pure and mixed infestation

\begin{tabular}{|c|c|c|c|c|c|c|c|c|}
\hline \multirow{2}{*}{$\begin{array}{l}\text { Utvrđene vrste parazita jetre } \\
\text { The established parasites of liver }\end{array}$} & \multicolumn{2}{|c|}{ Goveda / Cattle } & \multicolumn{2}{|c|}{ Junad / Beef cattle } & \multicolumn{2}{|c|}{ Telad/Calves } & \multicolumn{2}{|c|}{ Ovce / Sheep } \\
\hline & $\begin{array}{l}\text { Poz. } \\
\text { Pos. }\end{array}$ & $\%$ & $\begin{array}{l}\text { Poz. } \\
\text { Pos. }\end{array}$ & $\%$ & $\begin{array}{l}\text { Poz. } \\
\text { Pos. }\end{array}$ & $\%$ & $\begin{array}{l}\text { Poz. } \\
\text { Pos. }\end{array}$ & $\%$ \\
\hline Echinococcus polymorphus & 184 & 34,2 & 27 & 14,8 & - & - & 71 & 33,3 \\
\hline Dicrocoelium dendriticum & 62 & 11,5 & 14 & 7,69 & 8 & 0,8 & 18 & 8,45 \\
\hline Fasciola hepatica & 48 & 8,92 & 11 & 6,04 & 19 & 1,9 & 6 & 2,81 \\
\hline E. polymorphus + F.hepatica & 30 & 5,57 & 12 & 6,59 & - & - & 19 & 8,92 \\
\hline E. polymorphus + D.dendriticum & 96 & 17,8 & 8 & 4,39 & - & - & 77 & 36,2 \\
\hline E. polymorphus + F.hepatica + D.dendriticum & 2 & 0,37 & - & - & - & - & 7 & 3,28 \\
\hline F.hepatica + D.dendriticum & 6 & 1,11 & 1 & 0,54 & - & - & 3 & 1,4 \\
\hline \multirow[t]{2}{*}{$\begin{array}{l}\text { Utvrđene vrste parazita pluća } \\
\text { The established parasites of lungs }\end{array}$} & \multicolumn{2}{|c|}{ Goveda / Cattle } & \multicolumn{2}{|c|}{ Junad / Beef cattle } & \multicolumn{2}{|c|}{ Telad / Calves } & \multicolumn{2}{|c|}{ Ovce / Sheep } \\
\hline & $\begin{array}{l}\text { Poz. } \\
\text { Pos. }\end{array}$ & $\%$ & $\begin{array}{l}\text { Poz. } \\
\text { Pos. }\end{array}$ & $\%$ & $\begin{array}{l}\text { Poz. } \\
\text { Pos. }\end{array}$ & $\%$ & $\begin{array}{l}\text { Poz. } \\
\text { Pos. }\end{array}$ & $\%$ \\
\hline Echinococcus polymorphus & 272 & 50,6 & 48 & 26,4 & - & - & 151 & 70,9 \\
\hline
\end{tabular}

do $9,30 \%$ zimi, dok je za F. hepatica iznosio od 1,96\% u jesenjem do $10,71 \%$ u proljetnom razdoblju.

Kod teladi se infestiranost jetre $s D$. dendriticum kretala od $0,93 \%$ u jesen do $1,62 \%$ ljeti, a s $F$. hepatica od $1,05 \%$ zimi do $2,36 \%$ u proljeće. Kod teladi nisu registrirane miješane infestacije jetre. Naši su nalazi kod teladi s istog područja manji u odnosu na najveću invadiranost (17\%) s $D$. dendriticum i prevalencijom koja je bila najveća u kolovozu 53,8 \%, a najmanja u travnju i iznosila je 6,6\% (Zuko i sur., 1992./95. a). Slični podaci navedeni su u području sjeverozapadne Španjolske (Gonzalez-Lanza i sur., 1993.) s 37,64 \% pozitivnih nalaza na $D$. dendriticum, i s najvećim stupnjem infestacije $u$ razdoblju jesen-zima.

Prateći sezonsku dinamiku nalaza E. polymorphus, u jesen i proljeće $u$ jetri ovaca prevalencija infestiranosti bila je gotovo ista (32,89\% u proljeće i 33,57 \% zimi), a sličan je odnos registriran i u miješanoj infestaciji $E$. granulosus + D.dendriticum, E. granulosus $+F$. hepatica i $E$. granulosus $+D$. dendriticum $+F$. hepatica. Najčešći nalaz parazita u miješanoj infestaciji bio je za $E$. granulosus + $D$. dendriticum. Postotak infestacije za pojedinačne nalaze $D$. dendriticum i F. hepatica također je bio približan u jesen i proljeće. Prevalencija infestacije pluća ovaca s E. polymorphus kretala se od $69,73 \%$ u jesen do 71,53 $\%$ u proljeće.

Kao što je vidljivo iz dobivenih rezultata istraživanja, ciste E. polymorphus utvrđene su u najvećem postotku kod ovaca, zatim kod goveda i junadi, a kod teladi nisu registrirane. Osim E. polymorphus, ekonomski značajniji paraziti utvđeni u jetri bili su trematode $D$. dendriticum i $F$. hepatica. Mali metilj utvrđen je $s$ dvostruko većom prevalencijom infestiranosti od velikog metilja. Najmanji postotak infestacije bio je bobicom C. bovis, koji je registriran u samo osam životinja.

\section{ZAKLJUČCI}

Uspoređujući rezultate vlastitih istraživanja s istraživanjima drugih autora, možemo konstatirati da problem prije svega ehinokokoze životinja, ali i cisticerkoze, fascioloze i dikrocelioze, predstavlja ozbiljan i permanentan zdravstveni problem domaćih životinja na istraživanom području, ali i na prostoru cijele BiH. No u isto vrijeme to je i prijetnja zdravlju ljudi, dakle javnozdravstveni problem. Rješavanje tog problema zahtijeva sustavni pristup i uključivanje svih segmenata društva uz značajnu i kontinuiranu financijsku podršku tijekom dužeg vremenskog razdoblja na cijelom području države.

\section{LITERATURA}

Alagić, D., I. Gavrilović, A. H. Beganović(1964.): Razmatranje o ikričavosti goveda zaklanih na sarajevskoj klaonici. Veterinaria, 9, 2, 219224

Bjelica, G. (1964.): Paraziti ovaca opštine Konjic i neki uslovi njihovog pojavljivanja i širenja. Doktorska disertacija, Sarajevo.

Brglez, J., M. Kopitar (1983.): Prilog poznavanju epizootiologije invazioni bolesti ovaca u geografskim uslovima SR Slovenije. Vet. glasnik, 37, 11, 825-829.

Čanković, M., M. Rozman (1979.): Helmintofauna preživara na brdsko-planinskom području Bosne i Hercegovine. Zbornik radova IRC-Hepok Mostar, str. 423-434.

Čanković, M., A. Jažić (1988.): Parazitologija domaćih životinja (udžbenik) Sarajevo.

Hendrix, M. C. (1998): Diagnostic Veterinary Parasitology, Second Edition, Auburn University, Alabama, USA.

Ferizbegović, J., Š. Hadžibeganović, M. Čanković (1996.): Ehinokokoza domaćih životinja i ljudi na nekim područjima Bosne i Hercegovine za period 1988. do 1995. Zbornik radova I Savjetovanja veterinara Federacije Bosne i Hercegovine, Tuzla.

Gonzalez-Lanza, C., M. Y. Manga-Gonzalez, P. Del-Pozo-Carnero (1993): Coprological study of the Dicrocoelium dendriticum (Digenea) egg elimination by cattle in highland areas in Leon Province, northwest Spain. Parasitol Res; 79(6):488-91.

Iliev, A. (1985.): Epizootiološka slika i programi suzbijanja parazitoza kod ovaca u SR Makedoniji. Praxis veterinaria, 33, 1-2, 35-45.

Kassai, T. (1999): Veterinary Helminthology. Butterworth Heinemann, Great Britain. 
Kaufmann, J. (1996): Parasitic Infections of Domestic Animals. Birkhaus, Switzerland.

Lepojev, O., D. Beuković, Đ. Obradović (1985): Rasprostranjenost infekcije tenidama kod kontrolisano držanih pasa u Inđiji. Zbor. Mat. srp. za prirodne nauke, 68/85, 27-31.

Mijatović, I. (1964.): Rasprostranjenost ikričavosti goveda na području opštine Bihać. Vet. glasnik, 18, 4, 461465.

Pauković, Č., B. Kovačić, B. Majić, R. Rajković-Janje, M. Žutić, T. Naglić, Ż. Župančić (1988.): Aktuelna patologija i zdravstvena zaštita ovaca i koza u SR Hrvatskoj. Zbornik radova XII Savjetovanja o značaju zdravstvene zaštite u ovčarstvu i kozarstvu, Lipice, str 77-84.

Popović, B., N. Adžić (1988.): Stanje zaraznih i parazitarnih bolesti ovaca i koza u Crnoj Gori i poduzimanje mjera za njihovo suzbijanje. Zbornik radova XII Savjetovanja o značaju zdravstvene zaštite u ovčarstvu i kozarstvu, Lipice, str. 85-90.

Repač, S. (1985.): Nametničke bolesti i njihovo značenje. Praxis veterinaria, 33, 12 , 6769.

Rukavina, J. (1962.): „Problem tenijeze ljudi i cisticerkoze goveda i svinja u BiH. Veterinaria, XI, 1. 109 - 116. BoškovskiV. (Vlasenica) Usmena saopćenja 1958/60
Soulsby, E. J. L. (1986): Helmints, Arthropods and Protozoa of Domesticated animales. 7 th ed. Bailliere Tindall, London.

Šibalić, S., LJ. Cvetković (1987.): Parazitske bolesti domaćih životinja. (Il izdanje). Veterinaski fakultet, Beograd.

Toriano, P., A. Fasanella, A. Puccini (1994): Fauna elimentica degli ovini in Puglia. Atti SS Veterinaria, XLVIII, 2, 1295-1296. Italy

Zuko, A., M. Čanković, A. Jažić (1992./95. a): Trematodoze goveda travničke regije. Veterinaria, 41, 1-4, Sarajevo 1992/95.

Zuko, A., M. Čanković, A. Jažić (1992./95. b): Cestodoze goveda travničke regije. Veterinaria, 41,1-4, Sarajevo

Zuko, A., M. Čanković, A. Jažić, J. Omeragić, Z. Obradović (2000.): Ehinokokoza preživara na brdsko-planinaskim područjima Bosne i Hercegovine. Zbornik - Sastanak 0 ehinokokozi Sredozemnog područja, Split, Hrvatska

Zuko, A., A. Jažić, J. Omeragić, N. Sinanović, S. Mačkić (2005.): Helmintofauna preživara brdskog područja Bosne i Hercegovine. Veterinaria, 54, 15-24, Sarajevo.

Dostavljeno: 13.1.2017.

Prihvaćeno: 3.2.2017

\section{The most important parasites of ruminants from the Travnik area}

\section{SUMMARY}

On the basis of parasitological researches of internal organs and striated muscles 1,939 ruminants (1,006 calves, 182 beef cattle, 538 cattle and 213 sheep) of individual breeding on the region of the of Travnik, $39.65 \%$ of the animals was determined the presence of parasitic species of the Trematoda class and larval forms of the parasite of the Eucestoda class. Two species of trematode Fasciola hepatica and Dicrocoelium dendriticum and two larval forms of cestode Echinococcus polymorphus (species Echinococcus granulosus) and Cysticercus bovis (species Taenia saginata) were found. The highest total percentage of infestation of $29.55 \%$ was registered for cysts of Echinococcus polymorphus the most commonly found in the liver and lungs, and occasionally are located on the heart, spleen and kidney. Halfless has been established Dicrocoelium dendriticum 15,57\%, then Fasciola hepatica of 8,45 $\%$ and the lowest was Cysticercus bovis, only $0.41 \%$.

Key words: parasites, ruminants, trematoda, cestoda

\section{Bedeutende Parasitenarten bei Wiederkäuern im Raum von Travnik}

\section{ZUSAMMENFASSUNG}

Auf der Grundlage von parasitologischen Untersuchungen der inneren Organe und der Skelettmuskulatur von 1939 Wiederkäuern (1006 Kälber, 182 Jungviecher, 538 Rinder und 213 Schafe) aus individueller Aufzucht aus dem Raum der Gemeinde Travnik, wurde bei 39,65\% der Tiere die Anwesenheit von Parasiten aus der Klasse der Saugwürmer (Trematoda) sowie der Larvenformen der Parasiten aus der Klasse der Bandwürmer (Eucestoda) nachgewiesen. Es wurden vier Parasitenarten identifiziert, bzw. zwei Arten der Saugwürmer Fasciola hepatica und Dicrocoelium dendriticum und zwei Arten der Larvenform der Bandwürmer: Echinococcus polymorphus (Echinococcus granulosus) und Cysticercus bovis (Taenia saginata). Der größte Anteil des Befalls der untersuchten Wiederkäuer, bzw. 29,55\%, entfällt auf den cystösen Echinococcus polymorphus, der am häufigsten in der Leber und der Lunge und gelegentlich am Herzen, an der Milz und an den Nieren festgestellt wurde. Mit 15,57\% war der Anteil des Lanzettegels (Dicrocoelium dendriticu) doppelt so gering, während der Anteil des Großen Leberegels (Fasciola hepatica) 8,45\% betrug; der geringste Anteil mitnur 0,41\% wurde bei der Rinderfinne Cysticercus bovis festgestellt.

Schlüsselwörter: Parasiten, Wiederkäuer, Saugwürmer, Bandwürmer

\section{Especies importantes de los parásitos rumiantes de la región de Travnik}

\section{RESUMEN}

Basándose en los análisis parasitológicos de los intestinos y de los músculos estriados de 1.939 rumiantes (1.006 terneros, 182 novillos, 538 ganados vacunos y 213 ovejas) de la crianza individual, de la región del municipio de Travnik, en 39,65\% de los animales fueron determinados los parásitos trematodos y las larvas de la subclase Eucestodas. Fueron encontrados cuatro especies de parásitos, de los cuales dos fueron trematodos Fasciola hepatica y Dicrocoelium dendriticum, y dos especies de larvas Eucestodas, Echinococcus polymorphus (especie Echinococcus granulosus) y Cysticercus bovis (especie Taenia saginata). El porcentaje más alto de los rumiantes analisados infestados fue $29,55 \%$ con quistes causados por Echinococcus polymorphus predominantemente encontrados en el higado y en los pulmones y esporádicamente encontrados en los corazones, los bazos yen los riñones. El número dos veces menor fue encontrado para los Dicrocoelium dendriticum (15,57\%) y Fasciola hepatica (8,45\%), y el número más pequeño de sólo 0,41\% fue encontrado para los Cysticercus bovis.

Palabras claves: parásitos, rumiantes, trematodos, cestodos 


\section{Significative specie di parassiti dei ruminanti nel territorio di Travnik}

\section{SUNTO}

In base agli esami parassitologici eseguiti sugli organi interni e sul tessuto muscolare striato di 1.939 ruminanti (1.006 vitelli, 182 manzi, 538 buoi e 213 pecore) allevati in gabbiette individuali e provenienti dal territorio del comune di Travnik, nel 39,65\% degli animaliesaminati è stata accertata la presenza dispecie parassitarie appartenenti alla classe Trematodi e forme larvalidi parassiti appartenentialla sottoclasse Eucestodi. Sono state individuate quattro specie di parassiti, di cui due trematodi (Fasciola hepatica e Dicrocoelium dendriticum) e due in forma larvale appartenenti agli eucestodi: Echinococcus polymorphus (specie Echinococcus granulosus) e Cysticercus bovis (specie Taenia saginata). La maggior percentuale totale di infestazione dei ruminanti esaminati, pari al 29,55\%, è stata riscontrata in riferimento alle cisti dell'Echinococcus polymorphus, rinvenuta con maggior frequenza nel fegato e nei polmoni e, sporadicamente, nel cuore, nella milza e nei reni. Inferiore della metà è stata la percentuale riscontrata di Dicrocoelium dendriticum (15,57\%), seguita dalla Fasciola hepatica (8,45\%). Fanalino di coda le larve di Cysticercus bovis, con una percentuale del 0,41\%.

Parole chiave: parassiti, ruminanti, trematodi, cestodi

\section{UPUTE AUTORIMA}

$\bullet$

U časopisu MESO se objavljuju sve kategorije znanstvenih radova, stručni radovi, autorski pregledi, te izlaganja sa stručnih i znanstvenih skupova, kao i drugi tematski prihvatljivi članci na hrvatskom i engleskom jeziku.

Navedene kategorije radova podliježu recenziji.

\section{- Sadržaj i opseg rukopisa -}

Naslov rada treba biti što kraći. Ispod naslova navode se imena i prezimena autora. Svaki autor treba navesti: akademski stupanj, naziv i adresu organizacije u kojoj radi, zvanje i funkciju u organizaciji u kojoj je zaposlen. Radi lakšeg kontakta molimo autore da navedu broj telefona, telefaksa i elektroničku adresu (e-mail). Brojevi telefona i telefaksa neće biti objavljivani u časopisu.

Svaki rad mora imati sažetak na hrvatskom i engleskom jeziku. Neposredno ispod sažetka treba navesti tri do pet ključnih riječi.

Autorima citiranima u tekstu navodi se prezime i godina objavljivanja (u zagradi). Ako je citirani rad napisalo više od tri autora, navodi se prezime prvog autora uz oznaku i sur. te godina objavljivanja (u zagradi). U popisu literature autori se navode abecednim redom, i to na sljedeći način:

\section{a) rad u časopisu:}

Cvrtila Fleck, Ž., L. Kozačinski, B. Njari, D. Marenčić, G. Mršić, K. Špiranec, D. Špoljarić, M. Jelena Čop, M. Živković, M. Popović (2015): Technological properties and chemical composition of the meat of sheep fed with Agaricus bisporus supplement. Vet arhiv 85 (6), 591-600

\section{b) rad u zborniku:}

Bratulić, M., N. Cukon, Ž. Cvrtila Fleck, B. Njari, L. Kozačinski (2015): Hygienic and technological asppects of production of traditional fermented sausages in Istra county, Croatia. International scientific conference Hygiena alimentorum XXXVI, Strbske Pleso, 13.15 May, 2015. Proceedings, 236-239

\section{c) zbornik sažetaka:}

Pinter, N., L. Kozačinski, B. Njari, B. Mioković, Ž. Cvrtila Fleck, V. Dobranić, I. Filipović, N. Zdolec (2009): Integrirani sustav upravljanja. Znanstveno-stručni sastanak Veterinarska znanost i struka. Zagreb, listopad 2009., Zbornik sažetaka str. 48-49.

\section{d) knjiga:}

Njari, B., N. Zdolec (2012): Klaonička obrada i veterinarski pregled / Herak-Perković, Vlasta (ur.). Zagreb; Veterinarski fakultet Sveučilišta u Zagrebu, 2012.

Original rada (do 15 strojem pisanih stranica) treba imati sve slike, crteže i dijagrame. Prilozi (tablice, dijagrami $i$ slike) dostavljaju se zasebno, na posljednjoj stranici rada.

Legende slika i tablica moraju biti pisani na hrvatskom i engleskom jeziku. Grafikone je potrebno dostaviti i u jednom od grafičkih ili slikovnih formata $\left({ }^{*}\right.$.xls, ${ }^{*}$.tif ili $\left.{ }^{*} . j p g\right)$.

Rukopis s prilozima (tablice, dijagrami, sheme i crteži) dostavljaju se Uredništvu putem elektroničke pošte na jednu od adresa: meso@meso.hr/klidija@vef.hr / zcvrtila@vef.hr 